\title{
Surto de diarréia por rotavírus no município de Bom Jesus (PI)
}

\author{
Outbreak of diarrhea by rotavirus in Bom Jesus city, Piauí State
}

Telma M aria Evangelista de Araújo ${ }^{1}$

Jordânia M iranda Dantas ${ }^{2}$

Carlos Eduardo Feitosa Carvalho ${ }^{3}$

M aria Amélia de O liveira Costa 4

${ }^{1}$ Departamento de

Enfermagem, Centro de Ciências daSaúde,

UniversidadeFederal do

Piauí. Campus Universitário

dalninga, Ininga. 64049-550

Teresina PI.

telmaevangelista@gmail.com

${ }^{2}$ H ospital São M arcos.

${ }^{3}$ Estratégia deSaúdeda

Família.

${ }^{4}$ FaculdadeIntegral

Diferencial.
Abstract This study focused a diarrhea outbreak caused by rotavi rus in a city of Piauí State aiming to identify the etiology, protocol of assistance to cases. A case series was carried out with 22 children assisted for acute diarrhea in 2006 in Health Units of Bom Jesus city. The data were collected by means of interviews utilizing forms that were with the help of the children's parents and analysis of the appointment files was performed. M ost of the families (59.1\%) had a monthly income inferior to the minimum wage, $59.1 \%$ utilized septic cesspool, $77.3 \%$ consumed water from the public supply system and $54.5 \%$ did not drink filtered water. As to age, $54.5 \%$ ranged from one to four years, the majority of them featuring an adequate nutritional condition. Among the 22 samples rectal swab collected for coproculture, the following were isolated: E. coli (69.6\%), Klebsiella sp (95.6\%), Proteus M irabilis (47.8\%). Regarding the 16 samples of feces in natura for theassessment of rotavirus, $100 \%$ were positive for G2 genotype; $93.3 \%$ for P4 serotype and $7.2 \%$ were not typified. We concluded that a continuous monitoring of circulating genotypes is essential, which implies the need of training health professionals to tackle diarrhea down.

Key words Diarrhea, Rotavirus, Epidemiology, Control
Resumo 0 presente estudo trata de um surto de diarréia, por rotavírus, em um município piauiense, objetivando identificar a etiologia, protocolo para atendimento aos casos. Realizou-se um estudo do tipo série de casos, com 22 crianças atendidas com diarréia aguda em 2006, nas U nidades de Saúde do município de Bom Jesus. Os dados foram coletados mediante realização de entrevistas com formulário aplicado aos responsáveis pelas crianças e observações das fichas de atendimento. A maioria dasfamílias $(59,1 \%)$ tinha renda inferior a um salário mínimo, 59,1\% utilizavam fossa séptica, $77,3 \%$ consumiam água da rede de abastecimento pública e $54,5 \%$ não bebiam água filtrada. Com relação à idade, $54,5 \%$, tinham entre um a quatro anos e maioria apresentava estado nutricional adequado. Dentre as 22 amostras de swab retal coletadas para coprocultura, isolaram-se E. coli $(69,6 \%)$, Klebsiella sp. (95,6\%) ), Proteus M irabilis (47,8\%). Em relação às dezesseis amostras de fezes in natura para pesquisa de rotavírus, $100 \%$ foram positivas para 0 genótipo G2; 93,7\%, para o sorotipo P4 e 7,2\% não foram tipadas. Conclui-se que o monitoramento contínuo dos genótipos circulantes na população é fundamental, o que implica a necessidade de capacitação dos profissionais da área da saúde para o enfrentamento das diarréias. Palavras-chave Diarréia, Rotavírus, Epidemiologia, Controle 
Introdução

A doença diarréica aguda continua se constituindo em um problema de grande relevância epidemiológica no mundo, sendo uma das principais causas de morbimortalidade infantil, principalmente nos países subdesenvolvidos e em desenvolvimento, em face de acometer aproximadamente 1,3 bilhões crianças menores de cinco anos anualmente, produzindo quatro milhões demorte. Trata-se de uma síndrome que se apresenta de formas leves a graves, caracterizada pelo aumento do número de evacuações, com fezes aquosas ou de pouca consistência, frequentemente acompanhada de vômito, febre e dor abdominal; em alguns casos, há presença de muco e sangue. É considerada uma doença autolimitada, com duração entre dois a quatorze dias ${ }^{1}$.

As complicações ocorrem devido à desidratação eao desequilíbrio hidroeletrolítico, os quais são frequentementeassociados a tratamento instituído de forma inadequada, podendo, inclusive, causar o óbito, principalmente quando relacionados à desnutrição. Os episódios diarréicos repetidos podem ocasionar desnutrição crônica, com retardo do desenvolvimento estatoponderal e, até mesmo, da evolução intelectual ${ }^{2}$.

No Brasil, apesar dos importantes avanços al cançados na prevenção e controle das doenças infecciosas, as doenças diarréicas agudas, ainda permanecem como uma dos principais problemas de saúde pública e um grande desafio às autoridades sanitárias. De acordo com o M inistério da Saúde, a faixa etária mais acometida pelas diarréias no ano de 2004 foi a menor de um ano, com 813.830 casos, e a região mais atingida no período de 1996 a 2004 foi o Nordeste, que apresentou a maior proporção de óbitos por diarréia aguda ( $9 \%$ ) e os maiores gastos com internações hospitalares por esse agravo ${ }^{3,4}$.

As doenças diarréicas agudas são de etiologia diversificada, podendo ser causadas por bactérias, vírus ou enteroparasitas. Desde a descoberta dos primeiros agentes virais que especificamente causam diarréia no homem (os agentes de N orwalk), em 1972, estudosepidemiológicostêm revelado um número significativo de casos de diarréia aguda atribuídos a etiologia viral. Dentre os principais vírus atribuídos a esta patologia, podemos citar: rotavírus, calicivírus humanos (norovírus e sapovírus), astrovírus, adenovírus entéricos.

0 rotavírus éum dos mais importantes agentes etiológicos da doença diarréica nas crianças menores de cinco anos. Estima-se que todas as crianças aos cinco anos de idade já tenham sido infectadas por esses agentes. Nos países de clima temperado, são mais frequentes nos meses mais frios, enquanto nos tropicais ocorrem ao longo do ano. A infecção acontece em todas as idades, inclusiveem recém-nascidos, nos quaiséfrequentemente assintomática. Está associado a 30-50\% dos casos de diarréia grave e aproximadamente a um terço das hospitalizações por diarréia, contribuindo com 111.000 .000 episódios anualmenteem todo o mundo, com 800.000 mortes $^{3,6,7}$.

Os dados disponíveis na literatura atribuem ao rotavírus pelo menos $2 / 3$ das diarréias em crianças entre seis a vinte e quatro meses.Também esclarecem que as gastroenterites por rotavírus nas regiões temperadas e tropicais têm tendência sazonal, observando-seuma maior incidência nos meses mais secos. Por outro lado, este fenômeno não é significante nas regiões norte e nordeste ${ }^{8,9}$.

Descoberto por Bishop e colaboradores em M elbourne, Austrália, em 1973, o rotavírus pertence a um gênero de vírus RNA de $70 \mathrm{~mm}$ da família dos Reoviridae. Apresenta uma variedade decepas que diferem geneticamentee são classificadas em grupos, subgrupos e sorotipos. Foram identificados atéo momento sete grupos: $A$, $B, C, D, E, F$ e G; porém os patogênicos ao homem são os do grupo $A, B$ e $C$, sendo os do grupo $A$ mais frequentes nos seres humanos ${ }^{10}$.

Os sorotipos são determinados por duas proteínas (VP4 eVP7) situadas no capsídeo externo, as quais induzem a formação de anticorpos neutralizantes e são responsáveis pela classificação binária dos rotavírus $A$ em sorotipos $P$ e sorotipos $G$, respectivamente, sendo detectável pela maioria dos testes sorológicos. D os catorze sorotipos G(VP7) conhecidos, dez têm sido descritos como patógenos humanos: os tipos $\mathrm{G} 1$ a G4, os mais frequentemente encontrados em todo 0 mundo; os tipos G8 e G12, esporadicamente encontrados e o tipo G9, predominante na Índia. Rotavírus que eram encontrados exclusivamente como patógenos animais, sorotipos $\mathrm{G} 5, \mathrm{G} 6$ e G10, foram isolados em humanos. 0 sorotipo G5 foi encontrado em amostra brasileira ${ }^{11-13}$.

Foram detectados tipos incomuns de rotavírus em amostras humanas, como rotavírus $\mathrm{G} 5 \mathrm{e}$ $P$ [3], e misturas de tipos de rotavírus em uma mesma amostra. A presença de múltiplos tipos $\mathrm{G}$ e/ou $\mathrm{P}$ nas amostras, consistente com infecções causadas por mais de um tipo de rotavírus, ou seja, mistas, aumenta a chance de rearranjos genéticos durante infecções naturais e, por conseguinte, a emergência de cepas não usuais ${ }^{14}$.

Pesquisa sobre a epidemiologia das infecções por rotavírus no país, realizada por Linhares ${ }^{8} \mathrm{em}$ 
2000, afirma que na maioria das investigações encontra-se a predominância dos perfis "Iongos" (70\%), em geral compatíveis com os sorotipos G1, G3 e G4 (diversidade dos eletroferotipos de rotavírus: padrões obtidos à eletroforese- PAGE). $N$ ão obstante, em menor frequência, aqueles denominados de curtos, característicos do tipo G2, denotam configurações mais heterogêneas.

É importante registrar que pode haver nítida flutuação das frequências dos sorotipos circulantes predominantes, com destaque para o $\mathrm{Gl}$ e secundariamente, o G2 etal ocorrência é observada em escala mundial ${ }^{12}$. A mais extensa investigação realizada no Brasil, com vistas à caracterização genotípica do rotavírus, abrangeu nove estados, além do Distrito Federal, e os achados foram os que seguem: G1[P8]: 43\%; G2[P4]: 12\%; G3[P8]: $6 \%$ e G4[P8]: $6 \%$. Estudo longitudinal realizado na região norte, no período de 1983 a 1985, também observou que os tipos $\mathrm{G} 1$ e $\mathrm{G} 2$ prevaleceram com $50 \%$ e $30 \%$, respectivamente. Por outro lado, estudo subsequente, realizado no período de 1992 a 1994, revelou inversão, predominando o tipo G2 com $80 \%$, seguido do G1 com $20 \%$.

A ocorrência de reinfecções com um mesmo sorotipo (homotipias) e com sorotipos diferentes (heterotípicas) tem sido descrita principalmente em regiões com precárias condições de higiene ambiental. A gravidade do quadro clínico émaior durantea primeira infecção edecresce progressivamente a partir das demais ${ }^{4}$.

0 rotavírus age penetrando nos enterócitos, os quais se rompem e são substituídos por células absortivas imaturas. Essas se caracterizam por apresentar números reduzidos demicrovilosidades, embora conservem sua propriedade secretória. Observa-se redução da $\mathrm{Na} / \mathrm{K}$ ATPase, responsável pelo processo de absorção intestinal do $\mathrm{Na}$ acoplado à glicose, havendo redução da absorção deste assim como da água ${ }^{14}$.

Osníveis deAM P cíclico semantém inalterados, daí excluir-se o mecanismo secretório no contexto fisiopatológico das diarréias por rotavírus. Há também redução da atividade inerente às dissacaridases, principalmente da lactase, comprometendo o desdobramento dos dissacarídeos e sua absorção, promovendo um aumento da osmolaridade do lúmen intestinal e, consequentemente, aumento do fluxo de líquido. 0 açúcar não absorvido pode sofrer ação de bactérias que colonizam as porções mais distais do intestino, resultando na eliminação defezes com pH ácido, resultando na diarréia de natureza osmótica ${ }^{15,16}$.

Após um período de incubação de 24 a 48 horas, o quadro clínico, quase sempre, tem início com vômitos, febre, eliminação de fezes líquidas abundantes e 0 aparecimento dos sinais de desidratação, com duração, em média, de cinco a sete dias, podendo ocorrer a infecção de vias aéreas superiores em 20 a 40\% dos casos e intolerância a dissacarídeos e até mesmo monossacarídeos, de morando meses para reverter o quadro ${ }^{17,18}$.

Os rotavírus, eliminados em alta quantidade nas fezes de crianças infectadas, são transmitidos pela via fecal-oral, por água ou alimentos, por contato pessoa à pessoa, objetos contaminados e, provavelmente, também por secreções respiratórias, mecanismo que permite uma alta capacidade de alastramento dessa doença. 0 vírus pode se manter viável por horas nas mãos e por dias em superfícies sólidas ${ }^{15,18}$.

0 tratamento é o mesmo instituído para as doenças diarréicas agudas. É importante a reidratação oral e/ou parenteral (quando a reposição de fluidos e eletrólitos não for suficiente), para evitar as complicações (desidratação grave edistúrbios hidroeletrolíticos). 0 uso deantimicrobianos e antidiarréicos não é recomendado, pois geralmente evolui para a cura espontânea, devendo-se manter a dieta habitual ${ }^{19,20}$.

Com relação às medidas de prevenção e controle das gastroenterites por rotavírus, o Programa Nacional de Imunização do M inistério da Saúdeatual mente oferece aúnica estratégia efetiva e viável, que é uma nova vacina derivada de rotavírus humanos, disponibilizada de forma ampla e contínua para todas as regiões do país, desde janeiro de 2006. É indicada para os menores de seis meses deidade, para proteger as crianças de seis a vintee quatro meses, que são as mais susceptíveis às infecções por rotavírus enas quais se observa o maior número de complicações. Sabe-se que as medidas de saneamento básico e higiênicas em geral são importantes, porém não decisivas, haja vista que os indicadores de morbidade dos países desenvolvidos são similares aos do Terceiro Mundo ${ }^{1}$.

Diantedo exposto, destaca-sequeo quelevou as autoridades sanitárias a despertarem para a situação problema objeto deste estudo foi a elevação inesperada na incidência dos casos de diarréia nas semanas epidemiológicas de 29 a 36 de 2006, com destaque para a semana 33 , ultrapassando em 70\% (680 casos) o mesmo período, do ano anterior, além da ocorrência de um óbito por diarréia na semana 31. Por outro lado, sabe-se quea despeito da magnitude dos casos de gastroenterite por rotavírus, ainda são escassos os relatos de surto na literatura científica, o quejustifica a realização edivulgação deste estudo, o qual ob- 
jetivou identificar a etiologia do surto de diarréia ocorrido em Bom Jesus (PI); implementar protocolo para atendimento a casos de diarréia efornecer subsídios para melhorar o manejo clínico e a vigilância das doenças diarréicas.

\section{Método}

Trata-se de um estudo do tipo série de casos, sobre um surto de diarréia por rotavírus no município de Bom Jesus (PI), o qual se situa a 632 quilômetros da capital, Teresina e cuja população deacordo com o Sistema de Informação da Atenção Básica (SI AB/2005) éde 21.651 habitantes. 0 evento ocorreu no período de agosto a setembro de2006 (semana epidemiológica 29 a 36), acome tendo 22 crianças de zero a nove anos, as quais foram atendidas com diarréia aguda, em um hospital eem um centro de saúde do município.

Os dados sobre o surto foram coletados mediante real ização de entrevista utilizando-se um formulário, aplicado aos responsáveis pelas crianças, após a assinatura do termo de consentimento livre e esclarecido, contendo variáveis relacionadas aos dados sociodemográficos da família: renda, escolaridade, tipo dedomicílio, destino do lixo, redede esgoto, fonte de abastecimento de água e uso de água tratada. Para complementar as informaç̧̃es, foram realizadas observações das fichas de atendimento das crianças, onde se levantaram os dados referentes a sua condição biológica e clínica (sexo, idade, aleitamento materno, estado vacinal contra rotavírus, características da diarréia, grau de desidratação, uso de medicamentos antimicrobianos, internação hospitalar, duração do episódio diarréco, evolução). Em obediênciaà Resolução n ${ }^{196 /}$ 96 do Conselho Nacional de Saúde, para manuseio desses impressos, também foi solicitada a autorização por escrito dos gerentes do hospital e do centro de saúde onde as crianças foram atendidas. Em seguida, a pesquisa foi submetida à aprovação do ComitêdeÉtica daU UniversidadeFederal do Piauí (Parecer $n^{\circ}$ 12/2007).

Além do preenchimento destes formulários, também foram levantados os dados referentes aos outros procedimentos que foram realizados por ocasião do surto, conforme segue: coleta de fezes para coprocultura por meio de swab retal das 22 crianças e coleta de fezes in natura de dezesseis crianças para pesquisa de rotavírus; tratamento dos casos; busca ativa na comunidade; investigação de possíveis fal has na rede de abastecimento; coleta de amostras de água para análise microbiológica em sete pontos estratégicos da rede; atividades educativas junto à população; capacitação de profissionais para manejo do surto, distribuição de hipoclorito, dentre outras.

Em relação à coleta das fezes, foi realizada com saco coletor ou com auxílio de uma espátula a partir das fraldas das crianças participantes no estudo e acondicionadas em reservatórios de plástico impermeáveis devidamenteidentificados e armazenados sob congelamento. As amostras foram transportadas de acordo com as normas técnicas para o LACEN/PI e delá enviadas para 0 Instituto Evandro Chagas no Pará.

Para a análise dos resultados do estudo, foi construído um banco de dados, com a utilização do software SPSS versão 9.0, que calculou as estatísticas descritivas. A discussão foi feita com base na literatura produzida sobre o tema eà luz do programa de monitoramento das diarréias agudas (MDDA) do Ministério da Saúde.

\section{Resultados}

Notificou-se no período do surto 780 casos, dos quais 22 foram classificados como moderados a graves, sendo quinze hospitalizados. Os demais receberam tratamento nos domicílios. Alguns utilizaram o soro reidratante oral anterior ao atendimento realizado pelosprofissionais desaúde, por que já tinham o conhecimento prévio da sua eficácia e outros, por que receberam orientação e acompanhamento das equipes de saúde da família das áreas correspondentes.

A Tabela 1 apresenta as características sociodemográficas da população estudada. A maioria das famílias (59,1\%) tinha renda inferior a um salário mínimo, $68,2 \%$ possuíam entre quatro a oito anos de estudo, metade não tinha acesso ao sistema de coleta pública de lixo, 59,1\% utilizavam fossa séptica, $77,3 \%$ consumiam água da rede deabastecimento pública e 54,5\% não bebiam água filtrada.

Verifica-se que das 22 crianças pesquisadas, $50 \%$ eram do sexo masculino e $50 \%$, do sexo feminino. Com relação à idade, a maioria $(54,5 \%)$ estava na faixa entre um a quatro anos, a expressiva maioria $(81,5 \%)$ apresentava estado nutricional adequado, $59,1 \%$ não estavam mais em al eitamento materno, considerando que já se encontravam em idade de participar de um cardápio normal e apenas uma (4,5\%) havia recebido uma dose da vacina contra rotavírus (Tabela 2).

Com relação ao tratamento, pode ser observado, na Tabela 3, que dentre a totalidade das 
crianças estudadas, $68,3 \%$ foram internadas. Porém, nenhuma usou antimicrobiano. Com relação ao grau de desidratação, 68,3 \% apresen-

Tabela 1. Perfil sociodemográfico da população do estudo.

\begin{tabular}{lrr}
\hline Características & $\mathrm{n}$ & $\%$ \\
\hline Renda & & \\
$\quad$ < 1 salário & 13 & 59,1 \\
1 a 3 salários & 8 & 36,4 \\
> 3 salários & 1 & 4,5 \\
Escolaridade (em anos) & & \\
$\quad$ < 4 & 2 & 9,1 \\
4 a 8 & 15 & 68,2 \\
> 8 & 5 & 22,7 \\
Destino do lixo & & \\
Céu aberto & 11 & 50 \\
Coleta pública & 11 & 50 \\
Destino das fezes & & \\
Fossa séptica & 13 & 59,1 \\
Céu aberto & 8 & 36,4 \\
Latrina & 1 & 4,5 \\
Abastecimento água & & \\
Rede pública & 17 & 77,3 \\
Poço artesiano & 3 & 13,7 \\
Poço cacimbão & 1 & 4,5 \\
Cacimba & 1 & 4,5 \\
U so de filtro & & \\
Sim & 10 & 45,5 \\
Não & 12 & 54,5 \\
\hline
\end{tabular}

Tabela 2. Características das crianças do estudo. Bom Jesus (PI), 2006.

\begin{tabular}{lrr}
\hline \multicolumn{1}{c}{ Características } & $\mathrm{n}$ & $\%$ \\
\hline Sexo & & \\
$\quad$ Feminino & 11 & 50,0 \\
$\quad$ M asculino & 11 & 50,0 \\
Idade & & \\
$\quad<1$ ano & 6 & 27,3 \\
1 a 4 anos & 12 & 54,5 \\
5 a 9 anos & 4 & 18,2 \\
Estado nutricional & & \\
$\quad$ Baixo peso & 2 & 9,1 \\
$\quad$ Risco nutricional & 2 & 9,1 \\
$\quad$ Adequado p/idade & 18 & 81,8 \\
Em al eitamento & & \\
$\quad$ Sim & 9 & 40,9 \\
$\quad$ Não & 13 & 59,1 \\
Vacinação rotavírus & & \\
Sim & 1 & 4,5 \\
Não & 21 & 95,5 \\
\hline
\end{tabular}

tavam grau de moderado a grave e $54,5 \%$ utilizaram o plano de tratamento C, ou seja, terapia de reidratação venosa.

No tocante à pesquisa da água e das fezes colhidas, pôde-se verificar o que segue: das sete amostras de água para pesquisa microbiológica, apenas uma apresentou resultado positivo (contaminação por coliformes totais), não potável bacteriologicamente. No que diz respeito à pesquisa em humanos, das 22 amostras de swab retal para coprocultura, foram isolados os seguintes microorganismos: E. coli (69,6\%), Klebsiella sp. (95,6\%), Proteus M irabilis (47,8\%). Em relação às dezesseis amostras de fezes in natura para pesquisa de rotavírus, realizada pelo método enzimático (ELISA) KIT EIARA, 100\% foram positivos para a seguinte genotipagem: Sorotipo G: $100 \%$ G2 e Sorotipo P: $93,7 \%$ para P4 e 7,2\% não tipada, com $100 \%$ PAGE curto.

\section{Discussão}

O bservou-se que as características da população investigada são compatíveis com o evento em estudo, ou seja, considerando as diarréias como doenças de origem orofecal, frequentemente são encontradas entre famílias de baixa renda e que vivem em condições precárias de moradia. Por outro lado, éimportante considerar que as diarréias causadas por rotavírus podem acometer pessoas de qualquer nível socioeconômico.Tais

Tabela 3. Distribuição dos casos segundo internação, uso de antimicrobiano, grau de desidratação e plano de tratamento. Bom Jesus (PI), 2006.

\begin{tabular}{lcr}
\hline \multicolumn{1}{c}{ Variáveis } & $\mathrm{n}$ & $\%$ \\
\hline Internação & & \\
Sim & 15 & 68,3 \\
N ão & 07 & 31,8 \\
U so de antimicrobianos & & \\
Sim & - & - \\
Não & 22 & 100,0 \\
Grau de desidratação & & \\
$\quad$ Leve & 07 & 31,8 \\
Moderada & 08 & 36,5 \\
$\quad$ Grave & 07 & 31,8 \\
Plano de tratamento & & \\
A & 04 & 18,2 \\
B & 06 & 27,3 \\
C & 12 & 54,5 \\
\hline
\end{tabular}


resultados também foram observados em estudo semelhante realizado em Recife, no Instituto $M$ aterno Infantil de Pernambuco ${ }^{3}$.

Os dados relacionados à faixa etária foram concordantes com a maioria expressiva das pesquisas ${ }^{1,6}$, que afirmam que é na faixa entre seis a vinte equatro meses que se observa a mai or incidência de diarréia por rotavírus. Estudos têm demonstrado a persistência de anticorpos maternos transferidos passivamente ao longo do primeiro trimestre de vida, caindo dos seis aos sete meses. A partir do primeiro ano de vida, inicia-se uma elevação gradual de anticorpos, de modo que atéaos 34 meses, a expressiva maioria das crianças ( $80 \%$ ) se revelam positivas quanto à presença de I gG sérica para rotavírus ${ }^{19,20}$.

A proteção conferida por anticorpos maternos, transferidos passivamente, via aleitamento natural, é controversa. Pesquisa realizada em Belém, na década de oitenta ${ }^{18}$, não encontrou efeito protetor nítido $(p=0,21)$. Porém, investigação dirigida a enfermarias pediátricas de um hospital público de Belém ${ }^{21}$ revelou nítido efeito protetor $(p<0,05)$. A hipótese é que tal proteção só se manifeste diante de quadro clínico mais grave.

Quanto à baixa cobertura vacinal encontrada nesteestudo, podeser explicada pelo fato da vacina contra rotavírus ter sido implantada no país no início do ano de 2006, quando significativa parcela das crianças estudadas já estava fora do grupo-alvo. De acordo com o PNI 1, a idade máxima para iniciar a primeira dose são três mesese uma semana e para a segunda, cinco meses emeio. Trata-se de uma vacina monovalente, cujo sorotipo utilizado na sua composição éo G1[ \{P8\}] da cepa RIX 4414. Não obstante, seja especificamente eficaz contra esse sorotipo, oferece proteção cruzada para outras cepas não-G1 (G2, G3, G4, e G9). N esta perspectiva, a extensão da cobertura vacinal com a administração oportuna da vacina trará um impacto importante no perfil demorbimortalidade por rotavírus em todo o país, em função da ampla proteção oferecida.

Com relação à origem do surto em questão, as investigações apontaram para contatos que migraram da Bahia. O Piauí limita-se também com esse estado e o fluxo migratório entre eles é intenso, especialmente com as cidades do sul do Piauí, como é o caso de Bom Jesus. Assim, no período em que iniciou a elevação no número de casos, havia registro de que o vizinho estado também enfrentava surto semelhante. Ressalta-seque no nosso país, a sazonalidade deste agravo é variável. N os estados da região central, sul esudeste, a maior incidência éverificada nos mesesfrios ou no período de seca, entre maio a setembro. Porém, no nordeste se distribui por todo 0 ano.

Quanto à caracterização do sorotipo, os dados obtidos neste estudo mostraram que foram classificados como G2 P4 - PAGE curto, contrariando a maioria das pesquisas já realizadas ${ }^{21}$, as quais verificaram a predominância dos perfis longos.

Fato que merece destaque nesta investigação é que a maioria das crianças do estudo (68,3\%) apresentou desidratação que variou de moderada a grave e, mesmo frente à internação hospitalar, houve a opção pelos planos de tratamento $A$, em $18,2 \%$ dos casos, e B em $27,3 \%$. 0 plano A é indicado para os casos de diarréia sem desidratação e pacientes atendidos com cuidados domiciliares. $O$ plano B épara diarréia com desidratação e paciente em observação na sala de terapia de reidratação oral (TRO). E o plano $C$ é reservado para os casos de diarréia com desidratação grave, sendo necessária a hidratação venosa.

É importante salientar que muitas famílias do interior do município apresentam baixa escolaridade e, por conseguinte, absorvem menos as informações fornecidas. Soma-se a esses aspectos o fato de viverem sob precárias condições de moradia, o que levou os profissionais a optarem pela internação em alguns casos que poderiam ter recebido tratamento ambulatorial. Todavia, o tempo de internação foi curto. Outro ponto importante équenão houve prescrição de antimicrobianos, considerando que as diarréias, na sua maioria, são autolimitadas.

Sabe-sequea Organização M undial deSaúde (OMS), desde o início da década de oitenta, preconiza o uso de sais reidrantes orais no país, como uma alternativa de combateà desidratação levee até mesmo moderada, produzida pelas diarréias agudas, e esta prática tem se mostrado altamente eficaz, além de ser de baixo custo, baixa complexidade, fácil acesso e ampla aceitação pela população, especialmente do nordeste brasileiro.

A adoção de medidas de prevenção e controle das diarréias deve seguir um protocolo técnicooperacional ${ }^{22}$, tomando por base o processo sistemático de M onitorização das Doenças Diarréicas (MDDA), capaz de detectar precocemente os casos, para conferir agilidade na tomada de decisão.

Nessa perspectiva, o protocolo exige em primeira instância a identificação e notificação dos casos com coleta oportuna de amostras para exames, instituição de tratamento imediato, conformeas características da diarréia e presença ou não de desidratação, com sua respectiva classificação. Com o objetivo de definir a fonte de infecção e interromper a cadeia detransmissão, deve-se pro- 
ceder a investigação ebusca ativa dos casos econtatos e desencadear as medidas gerais de controle, as quais consistem em orientação sobre a qualidadeda água, destino adequado delixo e dejetos, controle de vetores, higiene pessoal e alimentar $\mathrm{e}$ educação em saúde. Considerando a importância das causas alimentares nas diarréias das crianças, é fundamental o incentivo ao al eitamento materno e a vacinação contra rotavírus.

\section{Considerações finais}

Os estudos epidemiológicos sobre as infecções por rotavírus no Brasil têm evidenciado a importância desses agentes no desenvolvimento das diarréias agudas, especialmente daquelas mais graves. N esse contexto, se faz necessária a imple mentação das medidas de vigilância epidemiológica das diarréias em geral.

Neste estudo, observou-se a adoção de um protocolo técnico-operacional padronizado para caracterizar o surto com precisão e desencadear as medidas pertinentes, quais sejam: notificação oportuna, com investigação dos casos e contatos; busca ativa de novos casos; investigação de fatores domiciliares (higiene e saneamento) e ambientais (destino do lixo, dejetos e qualidade da água de consumo humano), além de condi- ção clínica ligadaà desnutrição da criança; coleta e envio de material para exames, oportunamente; tratamento adequado dos casos e realização da vacinação com a vacina oral contra rotavírus de todas as crianças prioritárias.

Além das ações supracitadas, também fizeram parte do protocolo as atividades que seguem: orientações para a população em relação aos cuidados com a criança com diarréia por rotavírus, os quais são os mesmos para as diarréias em geral, lembrando que os casos podem ser mais graves nas menores de dois anos. Orientações às mães de crianças com início de sintomas de diarréia ou vômitos, sobre a oferta imediata de soro caseiro ou sais hidratantes e água tratada, para prevenir a desidratação, orientação para não suspender a alimentação e procurar imediatamente o serviço de saúde. $E$, finalmente, ressalta-se a importância dada ao treinamento dos profissionais para o enfretamento dos casos de diarréia.

Ao considerar a relevância dos problemas causados pelo rotavírus, o monitoramento contínuo dos genótipos circulantes na população é fundamental, especialmente neste momento, quando uma nova vacina está sendo administrada em larga escala, na população infantil, com vistas à detecção de rotavírus resistentes e surgimento de formas mistas.

\section{Colaboradores}

TME Araújo, JM Dantas, CEF Carvalho e M AO Costa participaram igualmente de todas as etapas da elaboração do artigo. 


\section{Referências}

1. Brasil. M inistério da Saúde. Informe técnico sobre a doença diarréica por rotavírus: vigilância epidemiológica e prevenção pela vacina oral de rotavírus. Brasília: M inistério da Saúde; 2005. [Versão preliminar]

2. Parashar UD, Hummelman EG, Breese JS, Miller M, Glass RI. Global illness and deaths caused by rotavirus disease in children. Emerg Infect Dis. 2003; 9:565-572.

3. Cauás RC, Falbo AR, Correia JB, Oliveira KMM M ontenegro FMU. Diarréia por rotavírus em crianças desnutridas hospitalizadas no Instituto $\mathrm{Ma}$ terno Infantil Prof. Fernando Figueira, IMIP. Rev. Bras. Saude M ater. Infant. 2006; 6:29-36.

4. Linhares AC. Epidemiologia das infecções por rotavírus no Brasil e os desafios para o seu controle. Cad Saude Publica 2000; 16:629-646.

5. Kurugöl Z, Geylani S, Karaca Y, Umay F, Erensoy S, Vardar F, Bak M, Yaprak I, Ozkinay F, Ozkinay C. Rotavirus gastroenteritis among children under five years of age in Izmir, Turkey.Turk J Pediatr. 2003; 45:290-294.

6. Linhares A. C. Rotavirus infection in Brazil: Epidemiology, immunity, and potential vaccination. Braz. j. infec. dis 1997; 1:284-293.

7. Rácz, ML, Candeias, JAN, Trabulsi, JR, Murakowsky J. Diarrheal diseases in Brazil: Clinical features of rotavirus-associated gastroenteritis in children. Eur J Epidemiol 1988; 4:382-385.

8. Linhares AC, Breese JS. Rotavirus vaccines and vaccination in Latin America. Pan Am J Public Health 2000; 8:305-331.

9. Cardoso DD, Martins RM, Kitajima EW, Barbosa AJ, Camarota SC, Azevedo MS. Rotavírus e adenovírus em crianças de $0-5$ anos hospitalizadas com ou sem gastroenterite em Goiânia-GO, Brasil. Rev. Inst. M ed. Trop. São Paulo 1992; 34:433-439. Bishop RF, Davidson GP, Holmes IH, Ruck BJ. Vi-

10. rus particles in epithelial cells of duodenal mucosa from children with viral gastroenteritis. Lancet 1973; 2:1281-1283.

11. Clements-Mann ML, Makhene M K, M rukowicz J, Wright PF, Hoshino $Y$, Midthun $K$, Sperber $E$, Karron $R$, Kapikian AZ. Safety and immunogenicity of live attenuated human-bovine (UK) reassortant rotavirus vaccines with VP7-specificity for serotypes $1,2,3$ or 4 in adults, children and infants. Vaccine 1999; 17:2715-2725.

12. Gouveia V, Santos N. Rotavirus serotype G5: An emerging cause of epidemic childhood diarrhoea. Vaccine 1999; 17:1291-1292.
13. Leite JPG, Alfieri AA, Woods PA, Glass RI, Gentsch $J R$. Rotavirus $G$ and $P$ typing circulating in Brazil: Characterization by RT-PC, probe hybridization, and sequence analysis. Arch Virol 1996; 141:2365-2374.

14. Timenetsky M CST, Gouveia V, Santos N, Carmona RCC, Hoshino Y. A novel human rotavirus serotype with dual G5-G11 specificity. J. Gen. Virol. 1997; 78:1373-1378.

15. Vranjac A. Diarréia e rotavírus. Rev. Saude Publica 2004; 38(6):844-845.

16. World Health Organization. Generic protocol to estimate the disease burden of rotavirus gastroenteritis in developing countries. Geneva: WHO; 2002.

17. Perez-Schael I, Guntinas MJ, Perez M, Pagone V, Rojas AM, Gonzalez R, Cunto W, Hoshino Y, Kapikian AZ. Efficacy of the rhesus rotavirus-based quadrivalent vaccine in infants and young children in Venezuela. N Engl J Med. 1997; 337:1181-1187.

18. Linhares AC. Epidemiologia das infecções por rotavírus no Brasil e os desafios para o seu controle. Cad Saude Publica 2000; 16(3):224-248.

19. Centers for Disease Control and Prevention. Intussusception among recipients of rotavirus vaccine United States, 1998-1999. M M WR 1999; 48:577-581.

20. Centers for Disease Control and Prevention. Withdrawal of rotavirus vaccine recommendation. M M WR, 1999; 48:1007-1011.

21. Gusmão RHP, M ascarenhas JDP, Gabbay YYB, LinsLainson Z, Ramos FLP, M onteiro TAF, Valente AS, Linhares AC. Rotavirus subgroup, $G$ serotypes, and electrophotetypes em cases of nosocomial infantile diarrhoea in Belém, Brazil. J Trop Pediatr 1999; 45:8186.

22. Brasil. Ministério da Saúde. Treinamento em monitorização das doenças diarréicas agudas. Caderno do treinando. Brasília: Ministério da Saúde; 2003.

Artigo apresentado em 17/04/2007

Aprovado em 24/08/2007

Versão final apresentada em 17/09/2007 